\title{
Solidarity in medicine: the role of medical students and young doctors
}

\author{
RICHARD V. LEE, M.D., MACP, FRGS
}

Professor of Medicine and Pediatrics and Obstetrics. Adjunct Professor of Anthropology and Social and Preventive Medicine. Director, Division of Maternal \& Adolescent Medicine. Director, Division of Geographic Medicine. Department of Medicine,

State University of New York at Buffalo, N.Y., U.S.A.

Article by invitation of the Editors. It is based in a lecture given by Dr. Lee at the World Congress of Internal Medicine, Santiago, Chile, November $11-15,2012$

Address correspondence to: Richard V. Lee, M.D. 7664 East Quaker Road, Orchard Park, NY 14127 Phone/fax: 716-667-3304 E-mail:dmdrvl@buffalo. edu

\begin{abstract}
The descriptions of medical caring and of highly technical specialism and science utilize different vocabularies and language. Medical caring has an ancient glossary of words, gestures, and behavior which is rapidly being transformed by specialization and advances in the technology of communication. The technologic capabilities of intensive care have, for example, exceeded the human life span and forced redefinition of the meaning of being alive. There are risks for the contemporary profession as linguistic and technical evolution proceed at a faster pace than the evolution of human health and illth. The accentuation and acceleration of generational disparity between the young and the old diminishes the solidarity of the profession and the quality of care that it provides.
\end{abstract}

(Rev Med Chile 2013; 141: 506-513).

Key words: General practice; Medical care; Solidarity; Specialization.

\section{Solidaridad en medicina: el rol de los estudiantes de medicina y de los médicos jóvenes}

Las descripciones históricamente aplicadas en la atención médica y las empleadas ahora, utilizan vocabularios y lenguaje diferentes, a raíz de la especialización altamente tecnificada y científica de la medicina. La atención médica recurre a un antiguo glosario de palabras, gestos y conducta que está siendo transformado rápidamente por la especialización y los progresos en tecnología de la comunicación. Por ejemplo, los recursos tecnológicos de los cuidados intensivos han modificado las expectativas de vida y han forzado a una re-definición del significado de "estar vivo". La profesión médica contemporánea enfrenta riesgos mientras la evolución lingüística y tecnológica avanza con mayor velocidad que la evolución natural de la salud y la enfermedad. La acentuación y aceleración de una disparidad generacional entre los jóvenes y los mayores disminuyen la solidaridad de la profesión y la calidad de la atención que provee.

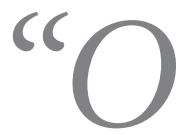
ne of the essential qualities of the clinician is interest in humanity, for the secret of the care of the patient is in caring for the patient". This is the closing sentence of what was one of the most widely read and respected of medical essays. Delivered as a lecture to Harvard medical students by Francis Weld Peabody in 1926, "The Care of the Patient," published in the Journal of the American Medical Association (JAMA) in
1927 , is a timeless commentary and description of what unites the profession of medicine. If there is a fundamental focus that coalesces physicians into solidarity, it is the care of the patient. There are trends in contemporary medicine that are disruptive, perhaps hostile, to the integration of science and humanity that is necessary for the well being of the profession. These trends are not new, but the advances and acceleration of molecular and 
genetic science and technical sophistication have exaggerated and exacerbated the divisions among clinicians, procedural technicians, and scientists.

Cardinal features of a profession are the accumulation of experience and wisdom and the capacity to incorporate new concepts, new facts, and new techniques into the body of knowledge and practice. It is the conglomerate unity of old and new that provides sustenance and spice for those that enter and remain in the profession. To embrace only the new and technical and to ignore the wealth of history and experience isolates a practitioner from the profession. Similarly, to avoid the new and technical and wallow only in the old and historical removes the practitioner from the growth and vigor of the profession.

There was a time at the beginning of my academic career when I would bring copies of the Sherlock Holmes canon to the lectures I gave to medical students at Yale and later at the University at Buffalo. I would read from them and remind my students that Sir Arthur Conan Doyle was trained as a physician and modeled his detective hero after two of his professors at the University of Edinburgh School of Medicine. In addition to the Holmes stories I would read from Conan Doyle's essay, "The Romance of Medicine," including this quote:

The moral training to keep a confidence inviolate, to act promptly on a sudden call, to keep your head in critical moments, to be kind yet strong-where can you, outside medicine, get such training as that? To the man who has mastered Gray's Anatomy life holds no further terrors.

Most of our present medical students today have never read A Study in Scarlet or opened a copy of Gray's Anatomy! For them "Grey's Anatomy" is a medical soap opera, not entirely different from another one about a drug addicted but brilliant eccentric called "Doctor House".

I would speak to the incoming first year medical students about my work with isolated Amerindian groups in the Brazilian Amazon, mountain villagers in the Northwestern Himalaya, and nomads of the northern deserts of Kenya. In those days having adventures, venturing into remote places to learn about and to provide some care for the inhabitants was exciting. The notion of medicine as a noble and gallant profession was not just romantic, it was inspiring. The adventuresome professor questing for knowledge, enduring natural and manmade treachery, surviving exotic hardships, offering the fruits of modern science to isolated, little known people and places, is a popular icon in the literature and folklore of the great civilizations of East and West. "Indiana Jones" is only the most recent incarnation of the heroic scholar. On occasion, I lament the increasingly apparent lack of romanticism and heroism in the medical education establishment of the United States.

The doctor detective, the learned professor with a passion for stories and poetry and a penchant for exploration, was a "role model" -a label that seems to have gone out of fashion. So for the last twenty years I have been politely and gradually going out of fashion and getting old. I still travel and teach. I write essays and stories, perhaps a little critical and, as my good friend and colleague -the editor of this journal-Professor Humberto Reyes, says, "curmudgeonly".

Perhaps it is best to start with the notion of "hero". Heroes and heroism are endangered entities nowadays. The popular media -egalitarian, anti-elitist- feeds upon celebrity and wealth; an interesting hypocrisy fostering appearance and avarice but demeaning the quiet doing good of ordinary seeming, but extraordinary people. Celebrity and heroism are not identical; they may coincide. Most heroes are not celebrities. Few celebrities are heroic. Modesty is an essential characteristic of genuine heroes.

The mythic hero described by Joseph Campbell must leave home on a mission, travel to foreign and strange lands, undergo trials and tribulations, succeed in fulfilling the mission's objectives, and return home. Travel into the unknown is essential. In mythic times travel was geographic: movement in space and time. Heroic journeys were most often over long distances and long time spans like the journeys of Hercules and Jason. The destinations were inhospitable; the inhabitants different and frequently bizarre like the Cyclops and the harpies that tormented Ulysses. More recent versions of the heroic myth and heroic journeys specify the mission as imaginative: an intellectual and scientific journey with travel into the unknown and dangerous carried out in laboratories and libraries.

A hero does not just travel and survive. Heroes return and change their world by telling their story and using the lessons learned and powers acquired to inspire their listeners. In addition to bravery and 
cleverness, the characteristic of a scholarly hero is linguistic aptitude: the capacity to communicate with multiple different creatures by word, gesture, or deed. Becoming a scholar hero diverts the individual away from the ordinary and familiar to a realm of the extraordinary, sometimes grotesque and cruel, sometimes sacred. Confrontation, combat, and compassion in the netherworld require a hero-in-making to be bold and brave but above all to learn.

"The best thing for disturbances of the spirit", replied Merlyn, beginning to puff and blow, "is to learn. That is the only thing that never fails. You may grow old and trembling in your anatomies, you may lie awake at night listening to the disorder of your veins, you may miss your only love and lose your moneys to a monster, you may see the world about you devastated by evil lunatics or know your honour trampled in the sewers of baser minds. There is only one thing for it then -to learn".

Merlin, advising the young Arthur ${ }^{1}$

Knowledge and skill, including a capacity for cleverness and disguise, allows a hero-to-be to return to the realm of ordinary and familiar where, because of newly acquired powers and knowledge, she or he could by generosity and example challenge and change the existing system of belief and practice. Neither the geographic nor the intellectual hero is silent or unsung. Heroes write and are written about. They make trouble, generate new ideas and behaviors, and dispel or disperse old rules and rulers. Our profession, medicine, for time out of mind has been a source of heroes, big and small, global and local.

C.P. Snow in his Rede lectures 50 years ago described the linguistic gulf between what we call the humanities -literature, art, music- and experimental, reductionist science. The debate, heated at times, focused on the unique languages of science and the arts as well as the people engaged in science and the people engaged in the humanities. That there are different languages emerging in the humanistic and the reductionist science camps of biomedicine is particularly well illustrated by the growing division between clinical practitioners that care for whole human beings and those that care for or investigate bits and pieces of human beings: organs, cells, subcellular constituents, and synthetic or mechanical facsimiles. Their different languages serve as a divisive boundary isolating generalists and specialists from one another, and by such division, setting in motion misunderstanding, mistrust, and missionary hostility. In medicine today the gulf between generalist, humanist care and specialized, reductionist science is growing and serious.

However, clinical medicine requires a common language, spoken and understood by scientists, clinicians, and patients and, just as important, shared by teachers and students of medicine. I fret that the evolution of clinical speech may lead to extinction of "antique" species of medical words and the concepts they embody. Replacing established words and concepts with neologisms and technical acronyms depletes the medical tongue of a rich linguistic history and a dictionary replete with wonderfully expressive, descriptive words that please the ear. On the other hand, the vitality of scientific medicine -practice and discourse- depends upon creative science and technology and the language necessary to describe their methods and products. The utility of clinical medicine-practice and discourse- depends upon the capacity of clinicians to converse with both science and patient, to tell the story.

Contained in the second volume of Gulliver's Travels is the sad story of the immortal Struldbruggs, one of the special groups that Captain Lemuel Gulliver encountered on his voyages ${ }^{2}$. As with all of Dean Swift's accounts of the Captain's voyages, there are lessons contained in this story that are useful beyond the satires of the $18^{\text {th }}$ century.

The Captain excited to learn of the existence of immortal creatures was quickly given a sobering lesson by his guide when he was taken to meet them in person.

"He gave me a particular account of the Struldbruggs among them. He said they commonly acted like mortals, 'til about 30 years old, after which by degrees they grew melancholy and dejected, increasing in both 'til they came to fourscore.

When they came to fourscore years, which is reckoned the extremity of living in this country, they had not only all the follies and infirmities of other old men, but many more which arose from the dreadful prospects of never dying. They were not only opinionative, peevish, covetous, morose, vain, talkative, but uncapable of friendship, and dead to all natural affection, which never descended below their grandchildren. 
The language of this country being always upon the flux, the Struldbruggs of one age do not understand those of another, neither are they able after 200 years to hold any conversation (farther than by a few general words) with their neighbors, the mortals, and thus they lie under the disadvantage of living like foreigners in their own country".

Struldbruggs reaching decrepitude are kept as wards of the state, lonely, depressed, irascible, their physical deterioration exacerbated and exaggerated by inability to comprehend the language of generations of mortals and immortals that follow them. Among the Struldbruggs there is no community; the different generations of Struldbruggs cannot converse with each other. Present day enthusiasm for longevity is an obvious target for essayists. Some authors have compared contemporary nursing homes to Swift's vision of Struldbruggian purgatory. Many clinicians caring for the seemingly unending accumulation of ills from overuse, abuse, organ failure, and simple "old age" marvel at the celebration for growing numbers of healthy elders with their impending disintegration. The extraordinary optimism for extending the human life span through transplantation, implantation of assistive devices, and molecular manipulation has risks described in another story.

Less than a century after Gulliver's Travels a story of reanimation and creation of a "human being" startled the public. When last observed the creature sewn together from multiple organs and pieces of different cadavers by Dr. Victor Frankenstein was trudging across the frozen, sterile wastes of Arctic ice after observing the body of its creator, who was intent upon its destruction ${ }^{3}$. The creature tells its story of abandonment, mistrust, desperate violence, and profound sadness and leaves, we know not to what end.

"To examine the causes of life, we must first have recourse to death. I became acquainted with the science of anatomy: but this was not sufficient; I must also observe the natural decay and corruption of the human body... Darkness had no effect upon my fancy; and a churchyard was to me merely the receptacle of bodies deprived of life, which, from being the seat of beauty and strength, had become food for the worm. Now I was led to examine the cause and progress of this decay, and forced to spend days and nights in vaults and charnel-houses.
After days and nights of incredible labour and fatigue, I succeeded in discovering the cause of generation and life; nay, more, I became myself capable of bestowing animation upon lifeless matter.

It was with these feelings that I began the creation of human being. As the minuteness of the parts formed a great hindrance to my speed, I resolved, contrary to my first intention, to make the being of a gigantic stature; that is to say, about eight feet in height, and proportionably large. After having formed this determination, and having spent some months in successfully collecting and arranging my materials, I began".

Mary Shelley's doctor took some big pieces (remember his creature was a virtual acromegalic), put them together and infused "the spark of being".

Victor Frankenstein did not like his creature! Consumed with fear and guilt and repulsed by its appearance, he rejected the chimera as a demon and monster. Indeed, the doctor did not consider his creature a human being at all. A collection of parts, even though anatomically correct and functional, did not satisfy Dr. Frankenstein's criteria for a complete, whole human life. The "spark of being" infused by the doctor gave life, but not humanity. Philosophical and religious beliefs meant that the creation of the creature was a breach of the doctor's professional and personal obligation; a parody of well-meaning science and medical care. The remainder of Victor Frankenstein's life was consumed by the pursuit of the creature with the intent to extinguish "the spark of being": revenge and redemption.

Medicine in the two hundred years before 1818 had advanced the study of gross and microscopic structures of organs, tissues, and cells; in essence by taking the body apart into smaller and smaller pieces. The youthful Mary Shelley, embedded in the romantic and poetic explosion of science and exploration at the end of the $18^{\text {th }}$ and the beginning of the $19^{\text {th }}$ centuries, exposed the anxieties and fascination that accompanied human intrusion into "nature", the danger of transforming the sacred into the profane. Her story relates the failure of the doctor to comprehend the nature of his creature and describes his disgust with the ugliness of a primitive thing made up of parts and pieces. The passion and despair of the story told by the monster resonates today in the medicine of organ 
oriented specialties and the decline of medical generalists, doctors of the whole creature.

Dr. Victor Frankenstein's reversal of anatomical dissection was perhaps a portent and predictor for the future of medical practice over the succeeding two hundred years. The notion that organs from the dead could be connected to create a human chimera, a conglomerate of different individuals, was a premonition of organ transplantability, organ specialization, and the quest for longer life, ultimately immortality.

Mary Shelley's "monster" was baffled by the lack of "humanity," acceptance, dignity, and love that he experienced. The bitterness of his rebuke, not only of his creator but of his creator's kind, can be heard in the pleas of many patients and some physicians wishing for a new modeling of the education and training for doctors; for retrenching the flight of medical students and trainees into the presumed easy life of algorithmic, cookbook specialization; for a revival of generalism and doctors for the whole patient, as well as for telling a good story. The flight of medical students and young doctors to organ-oriented specialties and encapsulated by the specific techniques and languages for their manipulation seems to me to have fulfilled Ortega y Gassett's prophecy of the "barbarity of specialism". Contemporary medicine and health care, with a growing acceptance and dominance of care dissected into organ and cellular pieces, has created something of a monster: a grotesque, expensive conglomerate, a chimera labeled the "health care system". Some patients have come to mistrust and to fear the "health care system". It is well to remember that contemporary modern hospitals are a habitat strange and forbidding to most of our patients.

The technical capacity to instrument, manipulate, and image the live patient is breathtaking, visually explosive. The desire to be able to see into and to watch the workings of a body is irresistible. The dangers of surgical, radiographic, and pharmaceutical science, of being able to see and then manipulate the human body and psyche, requires statistical skills in order to distinguish between the enthusiasm of doing and seeing and the efficacy of what was done and seen. Techniques and statistics with their unique language have by necessity and default become fundamental vocabularies of $21^{\text {st }}$ Century medicine. Sadly, they disconnect clinicians from the human experience because their practitioners and proponents eschew and forget older words and language for telling medical stories: the stories of patients as opposed to parts.

The decline of medical language of the physical examination is illustrated by what has happened to touch and touching ${ }^{4}$. Palpation has been and remains one of the major acts that establishes a bond between doctor and patient and provides information about the surfaces and the inner state of the patient's body. Touching a stranger requires bravery and trust; and the gentle act, innocent of barrier, rancor and malice, establishes the bond of healing. Medieval and Renaissance royalty were said to possess the power to heal scrofula by touching the patient: the King's touch. Medical touch, from gently feeling the patient's brow for heat to percussion and palpation, reveals enlargement of organs, the presence of abnormal structures, fluid collections in the thoracic and abdominal spaces, and the state of muscular activity and tension. In almost all traditional medicine taking the pulse is one of the fundamental techniques to get to know the patient and to establish a diagnostic and therapeutic connection.

Touching has always been risky. For time out of mind lepers have been "the untouchable". Unwelcome touch can precipitate withdrawal, hostility, and violent retaliation. Touching with unclean hands or clean fingers touching unclean skin were proven a century and a half ago to be capable of setting in motion fatal illness among parturient women. Three centuries earlier the explosive introduction of syphilis in Europe demonstrated the dangers of the most intimate of touches.

In the mid $19^{\text {th }}$ Century midwives and surgeons worked with bare hands. By the turn of the Century rubber gloves were used for invasive deliveries and surgeries. Today touching is done with barriers: gloves, condoms, sterile drapes and gowns. Even visual and olfactory "touch" is blunted by face masks. Today the appearance of the physician coming in contact with patients, automatically considered contaminated, is not much different than that of medieval physicians avoiding the plague. In 2012 medical touch is no longer innocent or safe. The cornucopia of germs, newly identified or newly resistant to antibiotics, has transformed medical touching. Medical rounds in the intensive care unit has become fundamentally rounds to look at charts, oscilloscopes, images: machine rounds, not patient rounds, because the doctors 
rarely touch their patients. Touching, massaging, palpating, moving the patient, is done by nurses and aides, rarely by doctors. At the end of the $20^{\text {th }}$ Century robotic devices allowed the surgeon to operate without even touching the patient with his or her fingers. The physical distance between patient and doctor has lengthened.

The physical examination has steadily diminished in both performance and practice. Patient presentations are cluttered with CT and MRI scans, echocardiograms, Doppler studies, and a vast array of laboratory tests. Only occasional mention is made of the verbal, auscultatory, palpatory, and olfactory state of the human subject. There are times, when making rounds, I feel that we are breathtakingly close to a science fiction scenario for the hospital of the future. Watch the activities in any intensive care unit ${ }^{4}$. You will see patients suffering the vicissitudes of baleful disease and malicious organ failure who are completely isolated much of the time from human warmth and sympathy. Here are human beings stripped of personal history, suspended in existence by respirators and intravenous pumps, preset and controlled by microcomputers. These fellow beings are often unable to talk or to hear, and they are often not engaged in conversation by morosely silent families and staff. Their "spark of life" is monitored at a distance by brightly lighted LCDs showing vital signs. Their excreta are silently funneled away by catheters and noisily suctioned off by someone wearing gloves and taking care not to touch the flesh. It is the absence of touching that dramatizes the intense loneliness of the desperately ill in our hospitals. They have become the modern lepers. It becomes easier to turn machines on and off when machines are more important, closer to us, than the living things to whom they are attached; just as quackery and fads thrive when other things -machines, money, science, theology, rights- are more important, closer to us, than the people we are supposed to serve.

Traditional clinical medical language is not quite dead and probably not at risk for extinction, but its body has been anatomized; having undergone pre-mortem autopsy. The explosion of information, imaging, laboratory and surgical technologies has transformed the sources and language of information, the capacities to record, organize and retrieve the literature as well as the patient's records so that it is possible to assemble an illustrated biography of each patient, their illness, and the details of their medical and surgical care. I fumble about with my Blackberry and iPad while the students and house staff I make rounds with whiz happily along retrieving images, operative reports, references and lab values. I am a plodder, out of date in their fast paced, digital world. To be sure there are moments when my history taking, physical examination, and experience provide facts and findings that are useful, illuminating, and reassuring. And there are places such as the remote Himalaya or Andes, the deserts of Africa, Asia, and South America, and disasters such as earthquakes and floods where, in the absence of electricity and transmitting towers, only my kind of medical information gathering works.

For me caring for a patient is based on conversation and physical contact: the history and physical examination. When listening to case presentations of patients admitted to the hospital from the emergency room with descriptions of the patient using only the language of computed tomography, magnetic resonance imaging and sonography, bypassing the patient history and physical examination beyond bare and inadequate abbreviations, I am discouraged, profoundly discouraged.

The language of medicine and medical practice that I learned is fast fading among our pupils. My vocabulary is often greeted by querulous apathy by students and house staff at morning report and on rounds. There are moments of silence, especially in response to my questions about the sequence of symptoms and physical findings. Why bother to do a careful physical examination of the chest reporting the observations of palpation, percussion, and voice maneuvers for pectoriloquy and egophony, when a computed tomographic scan is so easy to order? Their goal is rapid diagnosis, mine is to understand the course of illness in the patient. To them I am a Struldbruggian creature: disheveled, disgruntled, old fashioned, out of date, avoidable, irrelevant.

I am finding the linguistic plight of the Struldbruggs applicable to the contemporary medical situation. The vocabulary of medicine and biology has been transformed during the 50 plus years of my career in clinical medicine. It continues to change and to grow with startling rapidity. The methodology of recording, preserving and utilizing medical language is being transformed 
with equal acceleration. However, human illth has not changed as much as the ability to dissect, describe, and record the biology of disease. The possibility that the culture of medicine could be split into humanistic and reductionist camps has been something of a surprise even for the biomedical enterprise though that possibility had been dramatized in classic fiction of the $18^{\text {th }}$ and $19^{\text {th }}$ Centuries.

Perhaps the greatest weakness in today's medical education is that the vast majority is done in hospitals, clinics, laboratories, and lecture halls. Necessary venues to be sure, but confining to body, spirit, and curiosity of the pupils. Most of our medical students have little clinical experience outside of the sterile confines of hospitals and clinics filled with apparatus that does not go outside. Yes, they know of the world from their iPads and laptops and touristic adventure travels. Only a few have experienced the need for mobile, knowledgeable, handy medical workers in responding to natural events such as earthquakes, floods, and hurricanes. Humberto Reyes, my friend and editor of one of the oldest published medical journals in the New World, described the eye opening, extraordinary humanity of Chilean medical students and trainees responding to earthquakes in the Annals of Internal Medicine $e^{5}$. Obviously we cannot arrange fixtures for such events in the medical school curriculum! But we can certainly mobilize our students when such events do occur.

To my mind the present language of medical education is deficient in heroism and romance. I believe that the physician's role includes a certain amount of heroism including the concept of voyaging, the travel and adventures of mind and body that expand experience, cultivate curiosity and compassion, and generate the urge to describe and to inspire, to write and to teach. Furthermore rites of passage are fundamental events that shape the lives of novices and professors and require description and explanation. Medicine more than ever needs the adventure of voyaging: doctors that can leave the computer screen for the bedside, the patient's home, and the countries and cultures from which patients come. It does not need to be a long voyage, but it requires boldness, curiosity, and some risk. We need a reawakening of the heroic. Medicine should be a heroic voyage and its practitioners and professors heroic scholars or scholarly heroes, enmeshed in the connections among the spirit and body, environment and health, culture and care. I am not a hero of the mythic or fictional kind but I take seriously the criteria for hero-hood. I take issue with misguided regulations and pedagogy that make the process of becoming a physician comfortable, technically routine, risk averse, physically and spiritually bland. What most worries me in the present trend of clinical medicine and medical education is the substitution of a real person, a body, personality, and personhood with images, test values, and untestable reportage and descriptions by sonographers and radiographers who do not know and may not have ever seen the patient. We have created the "virtual patient" as described by Abraham Verghese.

Today, my students are as much my teachers as they are my pupils. Text messaging and acronymic exuberance have produced a written and spoken language without onomatopoeia: the sibilant sounds of whole words lost in a morass of acronyms, abbreviations, and jargon. At times the comedic mismatch between present trends and my digital retardation is unavoidable, hilarious, and reassuring. I am slowly learning how to navigate a new world of vocabulary, definitions, and machinery for which I have to thank my students.

Teaching has always been a two way thoroughfare. Most of my education in the digital realm has come from deft and generous students and house staff who, despite my curmudgeonly attitude about gadgets, have helped me expand my utilization and understanding of computers and the internet. I am still gawkingly slow compared to their nimble control of their devices, but they are patient and gentle. In the end it is the bond between student and teacher, youth and elders -the human contact- that shapes the future of our profession.

Fortunately contemporary Struldbruggs are made, not born. My lament could be addressed on two fronts. First, "old teachers" have an obligation to pay attention to their students; to listen and to learn about, if not master, the technology and language that dominates their personal and professional lives. Second, our youthful students have a similar obligation to pay attention to their old teachers; to learn and to practice what their predecessors may have been taught about the essentials of human contact by voice and touch, and to keep a cautious and skeptic attitude about technology. 
In the end, I find myself paraphrasing a paragraph from an essay I wrote 26 years ago as I was about to turn $50^{6}$. Age is as important as it is inevitable. Contemporary culture has been quick to dramatize the natural progression from flower to fruit to autumnal leaf as a kind of pathology. Growing old has become an illness. However, an old leaf is not a sick leaf. Sadly contemporary medicine fosters an erroneous allegory of autumn and aging by inadvertently isolating old doctors with incomprehensible linguistic and procedural jargon, by ignoring older language and procedure, and by labeling the old as effete or useless. The growing population of older physicians is in fact the cultural humus which will nurture the springtime youth. Discarding the alert, interested, educated and experienced cadre of "old docs" is cultural and professional fertilizer gone to waste. Few professions have been so prodigiously profligate with their heritage. If medical old-timers and medical youth become separated by language and practice then medicine as a profession devoted to patients as human beings is doomed. Medicine without soul!

\section{References}

1. White TH. The Sword in the Stone. William Collins Sons, London, 1938, p. 254.

2. Swift, Jonathan. Travels Into Several Remote Nations of the World. Benjamin Motte, London, 1726, Volume 2, pp. 127-46.

3. Shelley M. Frankenstein or the Modern Prometheus. Reprint of original manuscript, Bodlein Library, University of Oxford, 2008, pp. 75-82.

4. Lee RV. Touch. Amer J Med 1982; 73: 617-8.

5. Reyes H. Students response to disaster: a lesson for health care professional schools. Ann Intern Med 2010; 153: 658-60.

6. Lee RV. Autumn leaves. J Chronic Dis 1986; 39: 761-2. 